\title{
A PROLIFERAÇÃO DA CULTURA DO DESEMPENHO NA ESCOLA ATUAL: A GESTÃO DE SI NA NOVA GOVERNAMENTALIDADE
}

\author{
Ademir Henrique Manfré iD1
}

\section{Resumo}

O presente ensaio aborda o tema cultura do empresário de si. É resultado de elaborações teóricas e práticas desenvolvidas junto à disciplina de Currículo e Escola por mim ministrada em cursos de licenciaturas de uma Universidade do estado de São Paulo. Justificada por um conjunto de princípios provenientes do mercado neoliberal, essa cultura transfere os dispositivos empresariais - tais como a produtividade, a competitividade e o desempenho - para o âmbito pedagógico, subordinando os professores e estudantes a uma nova governamentalidade. Assim, temos como objetivo geral colocar em discussão o papel desempenhado pela racionalidade pedagógica empreendedora no direcionamento das formas de governo de si. Partimos dos seguintes questionamentos: por qual motivo inserir a cultura do empresário de si nas escolas? Essa cultura é suficiente para dirimir as desigualdades sociais conforme sugerido por seus defensores? O que temos feito de nós mesmos sob as formas de controle da vida? Partimos do pressuposto de que a cultura do empresário de si traduz-se naquilo que Foucault chamou de governamentalidade. Assim, a crítica foucaultiana à sociedade neoliberal emerge como um referencial teórico capaz de desenvolver em bases diferentes as concepções neoliberais as quais se inserem a Educação na atualidade.

Palavras-chave: Empresário de si; Governamentalidade; Contraconduta.

\section{THE PROLIFERATION OF PERFORMANCE CULTURE IN THE CURRENT SCHOOL: SELF-MANAGEMENT IN THE NEW GOVERNMENTALITY}

\section{Abstract}

In this essay we discuss the topic of self-entrepreneur culture. It is the result of theoretical and practical elaborations developed along the curriculum and school discipline I taught in undergraduate courses at a University of the State of São Paulo Such culture is justified by a set of principles from the neoliberal market, which transfers the business devices to the pedagogical scope. In other words, things like productivity, competitiveness and performance are subordinating teachers and students to a new governmentality. Hence, our objective is to analyze the role played by entrepreneurial pedagogical rationality in guiding the forms of self-government and the government of others. We started from the following questions: Why insert the culture of the self-entrepreneur in schools? Is this culture sufficient to solve social inequalities as suggested by authors who advocate it? What have we done with ourselves in the ways of life controlling? We start from the assumption that the self-

${ }^{1}$ Doutor em Educação pela Universidade Estadual Paulista/UNESP. Professor da Faculdade de Artes, Ciências, Letras e Educação/FACLEPP/UNOESTE. Atua nas licenciaturas presenciais e na Educação a Distância. E-mail: ademirmanfre@yahoo.com.br

(c) (1) (3) Perspectivas em Diálogo, Naviraí, v. 8, n. 16, p. 87-104, jan./abr. 2021. 
entrepreneur culture translates itself into what Foucault called governmentality. Therefore, Foucault's criticism of neoliberal society emerges as a theoretical framework capable of developing on different bases rather than those neoliberal conceptions to which school education is inserted today.

Keywords: Self-entrepreneur; Governmentality; Counter-conduct.

\section{Introdução}

O presente ensaio trata do tema cultura do empresário de si e Educação Escolar. É resultado de elaborações teóricas e práticas desenvolvidas junto à disciplina de Currículo e Escola por mim ministrada em cursos de licenciaturas de uma Universidade do estado de São Paulo.

De acordo com a História da Educação, a escola sempre foi alvo de políticas que visaram a preparação do indivíduo para o mundo do trabalho (BRASIL, 1996). $E$, na atualidade, o empreendedorismo é reconhecido e exaltado como um dos pilares para a Educação do século XXI, representado pela performance do sujeito empreendedor de si (DOLABELA, 1998, 2003, 2015; BRASIL, 2010a e 2010b; VILLELA, 2005; CARVALHO, 2004), do empresário de si como elemento essencial para se alcançar o almejado sucesso.

A cultura do empreendedorismo exerce sua atuação em todos os âmbitos da escola promovendo a competitividade como um dos pilares da educação atual (DELORS, 2010), pilar este sustentado pela racionalidade instrumental (aquisição de competências específicas para atuar no mercado competitivo) relegando a um segundo plano tudo aquilo que não pode ser categorizado numericamente.

Desse ponto de vista, o processo de ensino e de aprendizagem escolar fica restrito à aquisição de competências e habilidades emanadas dos organismos internacionais (Banco Mundial, Organização das Nações Unidas) e outras políticas neoliberais que orientam os rumos da Educação, traduzindo naquilo que Foucault (2008a) chamou de governamentalidade.

Chavões ${ }^{1}$ como "Pense fora da caixinha", "Enfrente desafios", "Vença seus medos", "Invista em si mesmo" são apresentados como fomentadores de comportamentos empreendedores. Surge o imperativo de que o empreendedorismo - como proposta formativa - deve ser seguido por todos/as.

Para se ter uma ideia do que estamos aqui tratando, no ano de 2017 a Bizword ${ }^{2}$ completou 20 anos de atuação educacional em mais de 100 países em todo o globo. Seu lema é capacitar estudantes a tornarem-se empreendedores de sucesso. No Brasil, a Junior Achievement ${ }^{3}$ surgiu com a missão de preparar estudantes - desde a Educação Infantil - a serem cidadãos qualificados.

${ }^{1}$ Extraído do vídeo "Kylee Majkowski de 10 anos quer ensinar empreendedorismo a crianças no Brasil". Disponível em: MAJKOWSKI, Kylee. Apresentação. In: Fórum da liberdade, Porto Alegre. Painel "Empreendedorismo", 2015. Disponível em: https://www.youtube.com/watch?v=xIg4qRGFKKQ. Acesso em: 23 out. 2020.

${ }^{2}$ A Bizword é um programa empresarial que surgiu no ano de 2000 nos EUA, atuando em mais de 100 países no mundo, desenvolvendo programas de empreendedorismo nas escolas de Ensino Fundamental e de Ensino Médio. Sua meta é preparar crianças e jovens para uma atuação empreendedora, engajando a educação para o empreendedorismo.

${ }^{3}$ Segundo seu site oficial, a Júnior Achievement é uma organização global sem fins lucrativos fundada em 1919 nos EUA. A referida oferece programas pedagógicos para a aplicação na Educação Básica. No Brasil, possui mais de 150 mil colaboradores atendendo cerca de 4 milhões de estudantes nos 27 
Pelo exposto até aqui, a figura do empreendedor passa a ser o novo modelo formativo requerido e exaltado como um dos principais suportes para a educação do futuro.

Desse ponto de vista, o modelo de conduta a ser desenvolvido pelos indivíduos é motivado pelo comportamento empreendedor: que vença o melhor, o mais preparado, o mais qualificado, reforçando a formação do empresário de si como elemento fundamental para se alcançar o sucesso.

Tendo em vista que a Educação se tornou um espaço governado pela competitividade e pelo empreendedorismo, pretendemos desenvolver em outras bases reflexões no âmbito da crítica foucaultiana aos dispositivos que orientam a formação escolar atual.

Concebemos que a reflexão filosófica emerge como um referencial teórico capaz de desenvolver em bases diferentes as concepções neoliberais as quais se inserem a educação escolar na atualidade.

\section{O empreendedorismo como modo de vida}

No curso "Nascimento da Biopolítica" - proferido em março de 1979 - Foucault analisou a Teoria do Capital Humano. Na compreensão do filósofo, o capital é entendido como tudo aquilo que é passível de produzir algum tipo de rendimento futuro. Desse ponto de vista, o desenvolvimento do capital liga-se à implementação e ao gerenciamento de competências e habilidades para desenvolver determinado trabalho. Exemplificando, um indivíduo que aplica dinheiro e dispende tempo em um curso técnico que promete qualificação imediata para o mercado de trabalho está realizando um investimento em si.

Como dito anteriormente, o rendimento é consubstanciado a partir de um certo capital, capital este reconhecido como "capital humano na medida em que, precisamente, a competência - máquina da qual é o rendimento não pode ser dissociada do indivíduo humano, que é o seu portador" (FOUCAULT, 2008b, p. 287).

No debate sobre competências e Educação, nota-se a insistente defesa de que o investimento permanente em si pode promover mais competências e habilidades, gerando a empregabilidade. Assim, o investimento em competências traduz-se numa técnica de marketing pessoal, isto é, numa gestão da vida diante de um modelo empresarial.

Sibila (2012) anotou que a busca por capacitações ou qualificações é resultado da lógica empresarial que ganha notoriedade espetacular na atualidade. Logo, essa lógica deve ser seguida por todos/as, pois quanto maior o investimento na aquisição de competências e de habilidades, maior será o potencial de empregabilidade.

Em consonância com o apontando acima, Dardot e Laval (2016, p. 332) referindo-se à produção do indivíduo competente e competitivo tão requerido pela sociedade neoliberal, afirmaram que o indivíduo empreendedor não calcula apenas investimentos e ganhos, mas "procura, sobretudo, trabalhar a si mesmo com o intuito de transformar-se, aprimorar-se, tornar-se sempre mais eficaz".

Assim, pela discussão desenvolvida até o momento fica explícita a ideia de que, se o indivíduo não conseguir uma vaga no competitivo mercado de trabalho, é porque

estados da federação. Sua missão é formar cidadãos qualificados e realizados, estimulando o desenvolvimento econômico do país. Disponível em: www.jabrasil.org.br. Acesso em: 14 jun. 2020.

(c) (1) () Perspectivas em Diálogo, Naviraí, v. 8, n. 16, p. 87-104, jan./abr. 2021. 
ele não gerenciou adequadamente a sua formação, não adquiriu competências suficientes para atingir o padrão de sucesso pessoal e profissional, tornando-se obsoleto como um objeto sem valor algum. Ao que parece, a escola é compreendida a partir de um viés utilitarista: que vença o melhor, o mais preparado, o mais capacitado.

Dentro da perspectiva foucaultiana de biopolítica, o poder de gerir a vida ${ }^{1}$ implica a racionalidade que consiste em produzir, tomar a vida e a sua inclusão nos cálculos. Nessa assertiva, a Biopolítica age sobre o corpo coletivo da população com o objetivo de regulá-lo. Trata-se, portanto, de um conjunto de técnicas de poder que orienta o comportamento da população no sentido de torna-la mais produtiva. No debate sobre competências e habilidades na educação escolar, essa regulamentação é notória, uma vez que ao indivíduo habilidoso e competitivo é prometido o almejado sucesso.

É nesse contexto que estamos chamando de gestão da vida que inserimos o debate sobre a cultura do empresário de si, ou seja, um dispositivo ${ }^{2}$ que produz "novos" potenciais de produção e de condução dos indivíduos.

Assim, o imperativo "ser competitivo consigo e com os outros" instaura-se no contexto educativo onde o "impulso competitivo torna-se um fim em si mesmo criando uma cultura de teste e de exibição e, é claro, uma corrida absoluta" (MASSCHELEIN; SIMONS, 2017, p. 124).

Pelo exposto acima, a função da escola é atingir a meta de "fabricar" um indivíduo competitivo, o empresário de si (SIBILA, 2012). Ao priorizar a preparação do indivíduo para o mercado de trabalho, alguns dispositivos de controle são definidos: lucratividade (investimentos em capital humano), utilidade (só devem ser ensinado aqueles conteúdos eleitos como úteis para o indivíduo sobreviver no mercado competitivo - o que não tem utilidade dentro desse objetivo deve permanecer fora dos muros escolares), calculabilidade (tudo deve ser racionalizado, programado), empregabilidade (formação rápida).

As recomendações sobre como se tornar um indivíduo competitivo não param por aqui. Se tomarmos a Base Nacional Comum Curricular (BRASIL, 2017a) referência obrigatória na elaboração dos currículos escolares e propostas pedagógicas de toda a Educação Básica - está presente a orientação de que os estudantes brasileiros necessitam desenvolver um número de competências básicas consideradas essenciais para se assegurar um futuro promissor. Capturados por um discurso econômico, o sucesso ou o fracasso depende única e exclusivamente de metas que o estudante necessita alcançar, enfatizando que todos/as devem ser empresários de si. Dito de outro modo, "a empregabilidade é a palavra em torno da

\footnotetext{
${ }^{1}$ Foucault utiliza a ideia de "gestão da população" no contexto da biopolítica. Desse modo, ao nos referirmos à "gestão da vida" estamos nos referindo às estratégias de poder que fazem parte do domínio dos aparelhos do Estado, bem como das instituições como escolas, empresas, dentre outras. 2 É no texto História da Sexualidade (A vontade de saber) que Foucault (1990) desenvolveu as definições de dispositivo, apesar de já ter apresentado tal conceito em Vigiar e Punir. Foucault (1990, p. 244) conceituou dispositivo como: [...] um conjunto decididamente heterogêneo que engloba discursos, instituições, organizações arquitetônicas, decisões regulamentares, leis, medidas administrativas, enunciados científicos, proposições filosóficas, morais e filantrópicas [o dispositivo pode ser entendido também] como um tipo de formação que, em determinado momento histórico teve como função principal responder a uma urgência histórica. O dispositivo tem, portanto, uma função estratégica dominante.
} 
qual o discurso e o pensamento sobre a escola são orientados hoje" (MASSCHELEIN; SIMONS, 2017, p. 88).

Quando o assunto é empreendedorismo na escola, Dolabela ${ }^{1}$ é o autor que mais se destaca na literatura brasileira. O autor afirmou que os estudos atuais indicam que o empreendedorismo abre novas oportunidades para que os indivíduos se qualifiquem, oferecendo, automaticamente, graus de realização pessoal.

Para tanto, precisam receber educação sobre empreendedorismo. Assim, não hesitarão em correr riscos, inovar, estabelecer vínculos e relações necessárias ao alcance dos objetivos, identificar oportunidades e buscar recursos onde estiverem. Tais comportamentos empreendedores têm mais importância do que as estruturas colocadas em jogo, porque têm embutido no seu âmago os valores do desenvolvimento (DOLABELA, 2015, p. 26).

Pelo exposto acima, é nítido que uma cultura empreendedora, estimulada desde a mais tenra idade, é oferecida como tábua de salvação para motivar e estimular nossos estudantes a adquirirem atitudes empreendedoras, para serem bem sucedidos na vida.

Nesse quadro que se apresenta, a educação é concebida como uma grande possibilidade para o desenvolvimento econômico do país. Aproveitando essa deixa, Dolabela (1998) afirmou que as escolas públicas não são suficientes em suas propostas educativas, sendo necessário investir em competências e habilidades, gerando criatividade e inovação.

O discurso empreendedor também é justificado dentro do debate das políticas públicas educacionais. Dois documentos publicados pelo governo federal nos chamam a atenção: o parecer CNE/CEB n 13/2010 (BRASIL, 2010), que tratou da inclusão do empreendedorismo como componente do currículo escolar desde a Educação Infantil, e o Decreto no 10.393, de 9 de junho de 2020, que institui a nova Estratégia Nacional de Educação Financeira - ENEF e o Fórum Brasileiro de Educação Financeira.

$O$ texto do Parecer CNE/CEB no 13/2010 inseriu a iminente necessidade da inclusão do empreendedorismo na escola, potencializando os valores da competitividade e lucratividade como eixos norteadores das políticas educacionais.

$\mathrm{Na}$ esteira da Pedagogia do Empresário de si, o Decreto n 10.393/2020 reproduziu as diretrizes emanadas do Relatório para a Unesco da Comissão Internacional sobre Educação para o século XXI (DELORS, 2010).

Os dois documentos propõem a inserção do empreendedorismo enquanto tema transversal na Educação Básica, fomentando um protagonismo em relação às demais disciplinas (DOLABELA, 2003).

Exemplificando o debate sobre empreendedorismo na escola, destacamos a seguir o Programa de Educação Empreendedora voltado a crianças do Ensino Infantil

1 Fernando Dolabela é um dos autores mais citados na literatura brasileira quando o assunto é Pedagogia Empreendedora. O autor é consultor da Confederação Nacional da Indústria (CNI) e do Conselho Nacional de Desenvolvimento Científico e Tecnológico (CNPq). Algumas obras publicadas: Empreendedorismo, a viagem do sonho; Empreendedorismo, uma forma de ser; Pedagogia Empreendedora, além de vários artigos publicados em revistas científicas. $O$ autor argumenta que 0 empreendedorismo é uma forma de ser e não simplesmente de fazer. Para ele, empreender é "engendrar formas de gerar e distribuir riquezas materiais e imateriais por meio de ideias, conhecimentos, teorias" (DOLABELA, 2015, p. 29). 
e do Ensino Fundamental, utilizado por muitas escolas privadas de São Paulo: Max, o empreendedog ${ }^{1}$.

O objetivo do referido programa é fomentar o talento das crianças identificando características empreendedoras, valorizando comportamentos estratégicos e incentivando a elaboração de Projetos de Vida. Dito de outro modo, desde a primeira infância, há o incentivo e a valorização do investimento em capital humano, vendendo a ideia de que para ser um vencedor na vida é necessário empreender logo no início, sem medos (DOLABELA, 2015).

Desse ponto de vista, o processo de ensino e de aprendizagem de conteúdos escolares se torna restrito ao desenvolvimento de competências e de habilidades. 0 trabalho docente é reduzido à execução de um trabalho instrumental cujo foco é o desenvolvimento de competências específicas.

A educação escolar constitui-se em ferramentas para o preparo do novo trabalhador o qual deve ter destreza em áreas específicas, deve desenvolver as chamadas competências para conseguir uma posição no mercado de trabalho. Dessa forma, ao ingressar nos mais diversos cursos preparatórios desde muito cedo, o aprendiz estará conquistando sua chance de empregabilidade no futuro. Nessa perspectiva de educação escolar, aprende-se ainda a criar o próprio emprego, caso ele não apareça: é o conhecido empreendedorismo ensinado desde a educação infantil nas escolas mais abastadas. Caso não consiga, será responsabilizado por sua falta de empenho, energia e vontade (ASSIS; LIMA, 2019, p. 44).

Diante do exposto, é nítido o prenúncio de um discurso sedutor amparado na ideia de progresso a qualquer custo. Basta o indivíduo ser empresário de si, almejar o aumento da riqueza do capital, do investimento em educação, do capital humano, consubstanciando a adesão a um estilo de vida, ao governo de si.

Villela (2005, p. 37) pontuou que, uma escola comprometida com o sucesso de seu estudante necessita seguir princípios-chave no quesito aquisição de competências e habilidades: "eficiência, suficiência, consistência e parcerias".

Tais concepções compreendem a escola como uma instituição cujo objetivo é fomentar o crescimento econômico. E essas concepções são fundamentadas por pedagogias e organizações multilaterais capazes de "promover uma pilotagem sobre o que deve ser ensinado nas escolas, e de que maneira isso deve ocorrer" (SANTOS, 2015, p. 94).

Ainda no debate sobre empresariamento de si, intelectuais como Perrenoud são conceituados como "um dos principais autores que apresentam o ensino por competências como uma possível alternativa ao fracasso escolar" (RICARDO, 2010, p. 612).

O conceito de competências formulado por Perrenoud é utilizado como referência por outros autores, inclusive brasileiros como Dolabela (2015) e Villela (2005) tratados neste ensaio.

\footnotetext{
${ }^{1}$ Trata-se de um sistema de ensino criado por uma pedagoga do conceituado colégio Objetivo de São Paulo. Um professor diferente, descolado personificado na figura de um cãozinho foi criado com o objetivo de ensinar práticas empreendedoras nas escolas brasileiras. Através do site da escola, é possível conhecer alguns materiais educativos. O referido programa foi exposto como uma metodologia de promoção empreendedora, abordando os seguintes pontos: alfabetização financeira, liderança, gestão, responsabilidade social, marketing pessoal (JÚNIOR, 2011).
} 
Define-se uma competência como a aptidão para enfrentar uma família de situações análogas, mobilizando de uma forma correta, rápida, pertinente e criativa múltiplos recursos cognitivos: saberes, capacidades, microcompetências, informações, valores, atitudes, esquemas de percepção, de avaliação e de raciocínio (PERRENOUD, 2000, p. 15).

É nessa perspectiva que Perrenoud (2000) propôs o desenvolvimento de competências como recursos indispensáveis a uma educação requerida pelo século XXI. Segundo o autor francês, o acúmulo de conhecimentos não garante a preparação do indivíduo para os novos cenários. É necessário aplicá-los, garantindo a integração dos indivíduos à cultura empreendedora.

Pela exposição acima, nota-se que ao indivíduo é depositada toda a responsabilidade em seu percurso formativo, desdobrado em práticas de autogoverno, de autoaprendizado.

Essa ênfase pela crescente aquisição de competências e de habilidades alcança centralidade no discurso pedagógico atual, apontando a Pedagogia Empreendedora como uma metodologia inovadora. Essa "lógica ocupa lugar tático no governamento sob a noção de sujeito que empreende a si mesmo" (CALIXTO, 2013, p. 28).

Assim, produz-se o perfil do sujeito empresário de si: flexível, inventivo, competitivo, adaptável. Dito de outro modo, muito mais do que gerir a própria carreira, produz-se uma forma de gerir a vida. Não importa o refletir. Leva-se em consideração apenas o produzir e o aplicar.

Diante do exposto, nota-se que a Pedagogia do empresário de si encarrega-se de "despertar" vocações empresariais nos estudantes, acrescentando que a ação empreendedora é caracterizada pela capacidade de gerar novos conhecimentos, sendo, portanto, oposta a uma escola obsoleta e sem vínculos com a realidade dos estudantes.

De acordo com Dolabela (2003), o que se pretende com a Pedagogia Empreendedora é gerar comportamentos e ações empreendedoras nos estudantes, dotando-os de saberes técnicos e instrumentais necessários à educação do futuro.

Na mesma linha de raciocínio de Dolabela (2003), Carvalho (2004, p. 13) afirmou que é fundamental uma educação empreendedora pautar-se em três princípios básicos: "liderança, energia e percepções".

No que se refere às práticas de ensino pautadas pelo empreendedorismo, várias Secretarias de Educação brasileiras recomendam propostas educacionais amparadas na educação empreendedora, sempre ancoradas na justificativa de que a educação vai mal porque temos ainda um modelo tradicional de ensino. Com esse discurso, a pedagogia empreendedora atravessa os currículos escolares, deixando pouca margem à reflexão e a modos de resistência.

Para se ter uma ideia do que estamos aqui tratando, o projeto "Oficina do Empreendedor" de autoria de Dolabela (1998), e em parceria com a ONG Visão Mundial, já atendeu cerca de 90.000 estudantes da educação básica em Minas Gerais, e 224.000 estudantes no estado do Paraná.

Depois do teste piloto desenvolvido nas cidades de Belo Horizonte e Japonvar (MG), em 2002, vários outros estados compraram esse projeto na tentativa de inovar as escolas. Até um prêmio foi criado para homenagear prefeitos empreendedores prêmio Mário Covas. Assim, o empresário de si necessita desenvolver: 
[...] habilidades e capacidades necessárias para criar uma empresa integrando os programas de ensino em todos os níveis: fundamental, médio e superior. Independentemente do nível de ensino, a ênfase deve ser concentrada no desenvolvimento da capacidade individual de procurar e identificar novas oportunidades (DOLABELA, 2003, p. 27).

Pelo exposto até aqui, nota-se que, desde a mais tenra idade, nossas crianças são estimuladas a investirem em capital humano, sendo orientadas a elaborarem planos de negócios, a estudarem Propaganda e Marketing, a desenvolverem comportamentos de liderança visando a aprendizagem de conceitos básicos, tornando-se, no futuro, prósperos empreendedores.

Ilustrando o debate sobre a produção do empresário de si, a fundação Júnior Achievement - uma organização educativa mantida por uma iniciativa privada norteamericana - é responsável pelo desenvolvimento de projetos pautados na Pedagogia Empreendedora em mais de 112 países, atendendo, aproximadamente, 6,5 milhões de estudantes (JúNIOR, 2011). Só no Brasil, mais de 500 mil estudantes participaram de seus programas, afirmou Júnior (2011).

Os programas da Júnior Achievement utilizam a metodologia conhecida como "Aprender-fazendo". De acordo com Júnior (2011), nessa proposta metodológica, os fundamentos do empreendedorismo são transmitidos através de exercícios, jogos, desafios, simulações.

Nota-se que apenas as competências técnicas são enfatizadas nessa proposta. Desse modo, se a escola tradicional não gera competências e habilidades em seus estudantes, resta à Pedagogia Empreendedora - enquanto dispositivo da governamentalidade neoliberal - proporcionar uma formação "sedutora", vendendoa como uma alternativa inovadora.

Outra proposta que nos faz compreender a Pedagogia do Empresário de si enquanto um dispositivo de controle, uma governamentalidade pautada em bases econômicas e neoliberais, é o "Prêmio Educação Empreendedora Brasil". Trata-se de uma iniciativa do Instituto Endeavor ${ }^{1}$ com o intuito de valorizar e divulgar experiências inovadoras de empreendedorismo no Ensino Superior.

O objetivo é reconhecer os profissionais que trabalham com o tema, transversal às demais disciplinas. Ninguém vai ensinar outra pessoa a ser empreendedora, mas o professor pode instigar essa característica em seus alunos (INSTITUTO ENDEAVOR, 2009, p. 37).

Diante desse cenário, projeta-se uma suposta "nova" arquitetura à formação escolar ancorada em critérios de eficiência e eficácia pautados nos interesses do mercado.

Diferentes pesquisadores ligados a uma perspectiva crítica têm se oposto à abordagem empresarial da escola, denunciando uma visão técnica e utilitarista da Educação.

Ball (2010) pontuou que, na cultura do empreendedorismo, a performatividade exigida por seus adeptos é um meio de controle social, não permitindo aos indivíduos a possibilidade de reflexão e de crítica.

${ }^{1}$ Desde 2000, no Brasil, o Instituto Endeavor atua como uma organização global sem fins lucrativos com a missão de estimular o desenvolvimento, o crescimento, a transformação e a inovação dos empreendedores no país. Disponível em: www.endeavor.org.br. Acesso em: 15 jun. 2020. 
De acordo com Torres (1996), trata-se de uma nova gestão da formação, gestão esta engendrada por organismos multilaterais alinhada a propostas de eficiência do sistema capitalista e a uma adequabilidade do indivíduo ao mercado de trabalho.

Dentro desse quadro de performatividade ${ }^{1}$, os indivíduos são estimulados a serem empresários de si, a agregarem valor a si, a melhorarem sua produtividade, "[...] devem se tornar sujeitos empreendedores que vivem suas vidas como um empreendimento do eu" (BALL, 2010, p. 51).

Em Nosella (2010), a cultura do desempenho ativa uma dimensão técnica e mecânica ao ato de ensinar/aprender, pois almeja metas, produtividade, resultados.

Alinhado ao pensamento de Nosella (2010), Afonso (2009, p. 49) anotou que, no campo educacional, desde a década de 1990, as políticas educativas vêm adotando um "ethos competitivo com ênfase nos resultados ou produtos dos sistemas educativos". Dito de outro modo, nessa lógica empreendedora, os indivíduos "passam a ser vistos apenas pelo prisma da produtividade" (SANTOS, 2009, p. 240).

Diante do assinalado, a Pedagogia do Empreendedorismo nos convoca a refletir sobre o modelo de indivíduo que almejamos formar: "é a empresa e na empresa que se dará a validação das competências com vistas à classificação e à remuneração" (RICARDO, 2010, p. 610).

Apontamos que a Pedagogia do empreendimento do eu pode reforçar dicotomias no interior das escolas, tais como formação para a autonomia x formação específica, formação x capacitação, cultura x utilitarismo.

A vinculação da formação de competências a programas de treinamento (coaching) ou às chamadas metodologias ativas comprova que não se trata de um processo de formação e desenvolvimento humano pleno, mas da produção de autômatos programados para reagir em conformidade com as expectativas sociais. As pessoas devem controlar as emoções como dirigir um automóvel sem precisar pensar no que estão fazendo para que possam funcionar adequadamente nas escolas, no trabalho ou na vida (SILVA, 2018, p. 151).

Trata-se, portanto, da adequação da Educação aos interesses econômicos, reduzindo a formação a fins lucrativos e utilitaristas. Em outras palavras, uma educação de qualidade é entendida pelo discurso empreendedor como aquela que prioriza a gestão do desempenho, da eficiência, do treinamento e do resultado (DOLABELA, 2015). Em nosso entendimento, uma educação pautada por competências e habilidades traduz-se no que Foucault (2015) caracterizou como biopolítica, em uma nova governamentalidade.

Diante da amplitude que caracteriza a temática, ressaltamos a seguir o debate filosófico-educacional no sentido de pensar a educação por outras bases que não o da cultura do empresário de si numa tentativa de resistência à cultura do desempenho. A partir dos conceitos de biopolítica, de contraconduta e de crítica apresentamos elementos analíticos contrários à racionalidade instrumental neoliberal.

1 Por performatividade, Ball (2010, p. 4) entendeu "uma tecnologia, uma cultura e um modo de regulação que se serve de críticas, comparações e exposições como meios de controle. Os desempenhos servem como medidas de produtividade e rendimentos, ou mostras de qualidade, ou ainda momentos de promoção e inspeção".

(1) (1) Perspectivas em Diálogo, Naviraí, v. 8, n. 16, p. 87-104, jan./abr. 2021. 


\section{Governamentalidade, biopolítica e educação}

A filosofia de Foucault promove uma importante possibilidade de se pensar de outro modo os discursos e práticas pedagógicas na atualidade.

Levando em consideração essa premissa, a Educação e outras instituições sociais (Presídios, Polícia, Religiões, etc.) são tomadas como elementos de um aparato biopolítico referente ao governo dos corpos.

No texto História da Sexualidade: a vontade de saber, Foucault (1990) amplia a compreensão do conceito de biopolítica argumentando que este transfigura-se como uma tecnologia política de governo que objetiva calcular para melhor governar os destinos da vida dos indivíduos. Por assim dizer, essa tecnologia é desenvolvida por técnicas e dispositivos assinalados por Foucault (1990, p. 132) como biopoder.

Este biopoder, sem a menor dúvida foi elemento indispensável ao desenvolvimento do capitalismo, que sóp ode ser garantido à custa da inserção controlada dos corpos no aparelho de produção e por meio de um ajustamento dos fenômenos de população aos processos econômicos. Mas, o capitalismo exigiu mais do que isso; foi-lhe necessário o crescimento tanto de seu reforço quanto de sua utilizabilidade e sua docilidade; foram-lhe necessários métodos de poder capazes de majorar as forças, as aptidões, a vida em geral, sem por isso torná-las mais difíceis de sujeitar [...].

Em Foucault (1990), a biopolítica ${ }^{1}$ se encarrega da vida dos indivíduos como um todo. Em outras palavras, a biopolítica transfigura-se como uma ação governamental, que visa incentivar a vida e eliminar partes dela consideradas perniciosas por meio de políticas autodirigidas. Diante de um cenário marcado por discursos do empreendimento de si, as populações sujeitam-se aos princípios do autoempreendedorismo, tornando-se presas do processo de subjetivação controlados pelo mercado.

Na Microfísica do poder, Foucault (2015, p. 154) designou biopolítica como "o que faz com a vida e seus mecanismos entrem no domínio dos cálculos explícitos, e faz do poder-saber um agente de transformação da vida humana".

Diante dessas considerações, a vida social é atravessada pela lógica econômica da biopolítica, subordinando as relações dos sujeitos entre si e consigo mesmos a valores de rendimento, competitividade e de lucratividade, elementos esses que se aproximam do debate sobre competências e habilidades tecido neste artigo.

Diante das novas reconfigurações educacionais (BRASIL, 2017a, 2017b, 2020), a constante ênfase na preparação do indivíduo para o mercado de trabalho acaba por incorporar o empreendedorismo no interior das escolas, e com ele, propostas formativas com o intuito de produzir estudantes empresários de si, no futuro atuando como proprietários de uma empresa, ou desenvolvendo competências e habilidades diante de suas possíveis escolhas.

\footnotetext{
${ }^{1}$ De acordo com Pellizzaro (2013), há uma diferença entre o biopoder praticado como disciplina e o biopoder praticado como controle (biopolítica). Como poder disciplinar, está relacionado com a disciplina dos corpos, práticas disciplinares sobre os corpos. Biopoder enquanto biopolítica é praticado enquanto estratégias de controle sobre a população, e não mais dos indivíduos em particular. Mesmo que a biopolítica tenha surgido posteriormente ao poder disciplinar, não ocorre uma sobreposição de um pelo outro.
} 
No curso Nascimento da Biopolítica - apresentado por Foucault em 1979 - são apresentadas referências sobre o conceito do homo oeconomicus. O primeiro ponto de destaque se refere ao entendimento desse conceito para a compreensão do indivíduo-parceiro da biopolítica que o guiará em áreas não diretamente econômicas: família, saúde, educação, etc.

Em outras palavras, o homo oeconomicus é aquele indivíduo que obedece, que se mobiliza para alcançar algum fim. Assim, autoriza-se uma série de intervenções, cuja finalidade é garantir seu modo de ação.

[...] é um empresário, e um empresário de si mesmo. Essa coisa é tão verdadeira que, praticamente, o objeto de todas as análises que fazem os neoliberais será substituir a cada instante, o homo economicus parceiro da troca por um homo economicus empresário de si mesmo, sendo ele próprio seu capital, sendo para si mesmo seu produtor, sendo para si mesmo a fonte de sua renda (FOUCAULT, 2008b, p. 47).

Foucault (2008b) observou que os indivíduos haviam se transformado em negociadores econômicos capazes de ampliar seus capitais humanos a partir de investimentos em si com o objetivo exclusivo de tornarem-se competitivos no mercado neoliberal ${ }^{1}$.

Diante do assinalado, "o homo oeconomicus é aquele que aceita a realidade" (FOUCAULT, 2008b, p. 366). Esse homem é orientado por condutas e preocupações econômicas, sendo, portanto, "eminentemente governável". Trata-se de uma individualidade produzida, sendo, ao mesmo tempo, produtor do biopoder que sobre ele atua, controlando-o, submetendo-o.

Foucault (2008b) concebeu que a biopolítica é a manifestação no contexto político do modo de vida do homem econômico, o qual deixa-se capturar docilmente pelas técnicas de modelagem de conduta por entender que essas aplicações são fundamentais para a realização de seus projetos, de seus desejos. No contexto educacional, esse pressuposto é marcado por propostas alinhadas à preparação de um indivíduo indexado aos reclames de uma Base Nacional Comum Curricular repleta de competências e de habilidades as quais devem nortear a aprendizagem.

O filósofo focou sua análise na questão das tecnologias neoliberais de governamento, a partir das quais é possível pensar o modo como os indivíduos são governados e que, no caso do debate sobre competências e habilidades, é possível notar o papel biopolítico que a Educação assumiu na atualidade ao justificar a aquisição de competências como única forma de o indivíduo produzir sua felicidade. "O indivíduo deve considerar-se ele próprio um fragmento de capital [...]. O indivíduo não é rigorosamente, uma força de trabalho, mas um capital de competências que acompanha um estilo de vida, um modo de vida [...] (LAZZARATO; NEGRI, 2011, p. 31).

Diante do exposto, conceber o indivíduo como homo oeconomicus é compreendê-lo como um indivíduo governamentalizável, ou seja, um indivíduo que não reflete, muito menos questiona o seu contexto. O que importa é o investimento que faz em si para se tornar útil ao mercado de trabalho, fabricando, portanto, um tipo de individualidade autointeressada e econômica. Assim, esse sujeito de

${ }^{1}$ Foucault (2008a) não estava interessado na análise econômica neoliberal, mas estava preocupado em como as subjetividades são moldadas diante do Neoliberalismo.

(c) (1) Perspectivas em Diálogo, Naviraí, v. 8, n. 16, p. 87-104, jan./abr. 2021. 
interesses, por aceitar docilmente a realidade em que habita, não almejará mudanças para a realização de seus desejos. Designam-se padrões de condutas na vida das pessoas a fim de desenvolverem uma lógica econômica privilegiada pelo projeto biopolítico. Fabricam-se indivíduos, padronizam-se suas condutas para os tornarem úteis e dóceis diante da proposta biopolítica esperada, tendo suas vontades padronizadas.

No campo do debate sobre a Pedagogia Empreendedora, nota-se que os indivíduos, ao se tornarem empresários de si, competitivos e eficientes são governados dessa maneira sem resistirem a essa forma de governo.

Tanto quanto "a escola disciplinar, agora em crise aguda, também a escola contemporânea toma o corpo e a vida das crianças como matéria farta para intervenções operacionalizadas a partir das novas figuras do governamento neoliberal" (CESAR, 2010, p. 232).

Em uma leitura foucaultiana, no cenário da biopolítica, competências e habilidades podem ser compreendidas como formas de assujeitamento ou, como uma forma de docilização das condutas. Dito de outro modo, um indivíduo mais habilidoso e mais competitivo - como está posto na Base Nacional Comum Curricular - se torna mais adestrado e dócil diante do poder dominante, pois "é dócil o corpo que pode ser submetido, utilizado, transformado, aperfeiçoado em função do poder" (FOUCAULT, 1987, p. 183).

E possível assinalar que, diante do debate sobre competências e habilidades, a escola ainda hoje produz disciplinamento, adestramento a partir de um conjunto de competências e habilidades tão requeridas para o indivíduo sobrevir na sociedade competitiva. Assim, um indivíduo competitivo, aquele que aprende a aprender, muitas vezes desvinculado do aprender a pensar, cumpre as regras das organizações que o levam a ser vistos como competente.

É possível enfatizar que, através da biopolítica, o imperativo das competências e habilidades escolares está voltado ao mercado de trabalho como forma de docilização e adestramento dos corpos.

Diante do exposto, cabe-nos agora desenvolver o conceito de crítica enquanto atitude contrária aos procedimentos que almejam governar os indivíduos dessa maneira. É nesse contexto que estamos chamando de empresariamento de si que acreditamos ser possível desenvolver possibilidades de contracondutas, apresentando outras bases para a compreensão da realidade mais ampla.

\section{Atitude crítica como contraconduta ao empresariamento de si}

O que temos feito de nós mesmos sob as formas de controle e adestramento da vida? Como resistir?

Com esses questionamentos iniciamos a reflexão sobre as formas como Foucault concebia a Filosofia enquanto modo de vida. E, para isso, o filósofo toma a crítica para questionar as verdades, as formas de dominação e os efeitos que elas têm sobre nós.

Em 1978, logo após dedicar estudos sobre contracondutas pastorais no período medieval, Foucault pronunciou a conferência "O que é a crítica". O filósofo se propôs a desenvolver a genealogia da atitude crítica aprofundando a tese de que a crítica enquanto atitude é originária das contracondutas pastorais. Em outras palavras, as contracondutas "são movimentos que procuram escapar da conduta dos outros, que 
procuram definir para cada um a maneira de se conduzir" (FOUCAULT, 1999, p. 256257).

Ao evidenciar o termo contraconduta para referir-se ao poder de resistência pastoral, Foucault (1999) objetivou mostrar o aspecto ativo das revoltas de condutas. Dito de outro modo, as formas de dominação contra a quais elas insurgem é uma forma de poder que almeja para si a conduta dos indivíduos, regrando a relação dos indivíduos com os outros.

A contraconduta traduz-se na busca de uma conduta outra, de ser conduzido e conduzir-se de uma forma diferente, "no sentido de luta contra os procedimentos postos em prática para conduzir os outros" (FOUCAULT, 2008a, p. 266).

Diante do cenário posto pela Pedagogia das competências, qual relação tem a atitude crítica com o empresário de si (do governo de si)?

Para responder esse questionamento, vamos seguir a proposta argumentativa de Foucault (1990), segundo a qual, no contexto da governamentalização neoliberal, a ideia central de resistência, de contraconduta, é a questão de como não ser governado de tal maneira. Em Foucault (1999, p. 35): [...] a crítica é o movimento pelo qual o sujeito se outorga o direito de interrogar a verdade sobre os seus efeitos de poder e o poder sobre os seus discursos de verdade, a crítica seria assim a arte da insubmissão voluntária, a da indocilidade refletida.

A perspectiva crítica foucaultiana que adotamos para analisar as propostas de formação baseadas na pedagogia do empresário de si consiste na recusa de os indivíduos a se deixarem conduzir de uma determinada maneira (pelos princípios da competitividade, lucratividade, empreendedorismo). É uma maneira de resistência às diferentes formas de dominação, principalmente em um contexto marcado pela intensificação das formas de governar, de gerenciar a vida, do empresário de si.

No texto "O que é a crítica? Um ensaio sobre as virtudes de Foucault" Butler (2013, p. 159) iniciou a discussão com o seguinte questionamento: o que é oferecer uma crítica?

A filósofa apontou que necessitamos pensar a crítica enquanto prática filosófica, que coloque em questão os limites dos nossos modos de gerenciar os saberes. Ou seja, nesses termos, é ultrapassar o previamente determinado e regulamentado por programas e propostas educativas, tais como as apresentadas pela Pedagogia das competências e habilidades.

Segundo Butler (2013, p. 166), o que está em jogo não são simplesmente os comportamentos programados, mas as problematizações acerca das práticas pelas quais os indivíduos empreendem a si. Dito de outra maneira, "a prática crítica implicará a transformação do eu na sua relação com a regra de conduta".

$\mathrm{Na}$ leitura foucaultiana, a crítica inicia-se quando colocamos em análise a emergente necessidade de uma obediência aos imperativos neoliberais, submetendo os dispositivos de controle (a exemplo da racionalidade instrumental e empresarial) a um exame reflexivo.

O próprio Foucault (1999, p. 28) tensionou seu pensamento inaugurando uma atitude política: "a arte de não ser governado, ou melhor, a arte de não ser governado desse modo e aquele preço".

De modo velado, nota-se que a contraconduta foucaultiana é manifestada através da própria reflexividade que toma para si a viabilidade para a formação.

Butler (2013) anotou que Foucault entendeu a crítica enquanto possibilidade de resistência à governamentalidade neoliberal. 
No debate sobre a Pedagogia do empresário de si, observou-se o quanto a possibilidade de atitude crítica fora sonegada. Apenas o governo de si e dos outros nesse referencial neoliberal é fomentado.

Desse modo, ao tomarmos o ensaio "O que é crítica" propomos pensar em bases outras o modo como o indivíduo relaciona-se consigo e com os outros, que não pelos imperativos empresariais, mas enquanto possibilidade de abrir um campo filosófico reflexivo como problematização de si mesmo. A autonomia que decorre da atitude crítica não ocorre fora das relações de poder. Entretanto, ao promover a transformação dos mecanismos de dominação, a atitude crítica insere nos indivíduos a condição de fazerem uso de seu entendimento, concebeu Foucault (1999).

Assim, Foucault (1999) entendeu as origens da atitude crítica enquanto contraponto ao processo histórico das artes do governo de si, ou seja, como uma "maneira de desconfiar delas, de recusá-las, de limitá-las, de encontrar uma justa medida, de transformá-las, de procurar escapar" (ANASTASIO, 2017, p. 125).

\section{Considerações inconclusivas}

O presente ensaio abordou o tema "cultura do desempenho na escola" que penetrou no debate educacional brasileiro nos últimos anos. Essa cultura transfere os dispositivos neoliberais, tais como produtividade, desempenho a qualquer preço, competitividade, geração de competências e habilidades ao âmbito escolar subordinando professores e estudantes a uma suposta governamentalidade.

Há o discurso massivo (DOLABELA, 1998, 2003, 2015; VILLELA, 2005; CARVALHO, 2004) que a cultura empreendedora é fundamental para a produção capitalista, a qual almeja trabalhadores polivalentes, competitivos, colaborativos com possibilidades de aprender a aprender constantemente - processo esse desvinculado do aprender a refletir, a criticar e a resistir.

Logo, o empresário de si é a nova aposta vendida na atualidade, aquele que por si deve buscar competências e habilidades para ser um vencedor, saindo da "caixinha" e dos chamados modelos tradicionais de educação. Nessa percepção, a escola é atacada por não ser prazerosa, por não conectar o estudante à realidade empreendedora.

A partir da análise foucaultiana de biopolítica e de governamentalidade, defendeu-se que a Pedagogia das competências funciona como um dispositivo de controle voltado à sujeição e à docilidade, impedindo que os indivíduos se tornem resilientes ao status quo.

Em Foucault (2008b), abordou-se que o homo oeconomicus é aquele que, introjetado pela lógica econômica neoliberal, não é senão um empreendedor de trocas, mas também um empresário de si mesmo. Dito de outro modo, o neoliberalismo encara o indivíduo como um ser econômico ativo, como aquele que necessita desenvolver competências e habilidades para ser bem sucedido no mercado competitivo.

Com a pergunta "O que temos feito de nós mesmos sob as formas de controle da vida?" iniciamos a reflexão sobre como podemos pensar outros modos de vida. E para isso, tomamos o conceito de crítica para questionar as formas de dominação e os efeitos que elas têm sobre nós, pois "[...] a crítica é a arte da insubmissão voluntária" (FOUCAULT, 1999, p. 35). 
Assim, a perspectiva crítica aqui retomada a qual adotamos para analisar as propostas de formação baseadas na pedagogia do empresário de si consiste na recusa de os indivíduos deixarem de se conduzir de uma determinada maneira (princípios da competitividade, da eficiência, do empresariamento de si).

Desenvolver uma atitude crítica é ultrapassar o previamente designado por programas e propostas educativas alinhadas à racionalidade neoliberal.

Concluímos que a Pedagogia do empresário de si universaliza a racionalidade empresarial, excluindo o debate filosófico-educacional de uma análise mais ampla e profunda daquilo que ocorre na escola contemporânea.

Diante dessa perspectiva que transformou os atores escolares em meros construtores dóceis de seus empresariamentos, reivindicamos a possibilidade de contracondutas outras, aquelas afastadas da racionalidade neoliberal.

\section{REFERÊNCIAS}

AFONSO, Almerindo. Avaliação educacional: regulação e emancipação para uma sociologia das políticas avaliativas contemporâneas. São Paulo: Cortez, 2009.

ANASTASIO, Lara. Foucault: atitude crítica e seu lugar na modernidade. Revista Doispontos: Curitiba, São Carlos, v. 14, n. 1, p. 121-133, jan./abr. 2017.

Disponível em: https://revistas.ufpr.br/doispontos/article/view/48667. Acesso em: 25 fev. 2020.

ASSIS, Camila; LIMA, Laís. Subjetividade docente em tempos de cultura da performatividade. Revista Tecnia, v. 4, n. 1, p. 41-51, jan./jun. 2019. Disponível em: http://revistas.ifg.edu.br/tecnia/article/view/292. Acesso em: 27 out. 2020.

BALL, Stephen. Performatividades e fabricações na economia educacional: rumo a uma sociedade performativa. Educação e Realidade, v. 2, n. 35, p. 37-55, maio/ago. 2010. Disponível em: https://seer.ufrgs.br/educacaoerealidade/article/view/15865. Acesso em: 01 jun. 2020.

BRASIL, Base Nacional Comum Curricular. Brasília: MEC, 2017a. Disponível em: www.basenacionalcomum.mec.gov.br. Acesso em: 12 maio 2020.

BRASIL. Decreto no 10. 393, de 9 de junho de 2020. Institui a nova Estratégia Nacional de Educação Financeira - ENEF e o Fórum Brasileiro de Educação Financeira - FBEF. Diário Oficial da União, Brasília, 10 jun. 2020. Disponível em: http://www.planalto.gov.br/ccivil_03/_Ato20192022/2020/Decreto/D10393.htm\#art10. Acesso em: 14 set. 2020.

BRASIL. Lei n 13. 415, de 16 de fevereiro de 2017. Altera a Lei n 9394/96, de 20 de dezembro de 1996, 2017b. Disponível em:

http://www.planalto.gov.br/ccivil_03/_ato2015-2018/2017/lei/l13415.htm. Acesso em: 12 jan. 2020. 
BRASIL. Lei n 9394/96, de 20 de dezembro de 1996. Estabelece as Diretrizes e Bases da Educação Nacional. Disponível em:

http://www.planalto.gov.br/ccivil_03/leis/19394.htm. Acesso em: 20 fev. 2020.

BRASIL. Parecer CNE/CEB n ${ }^{13}$, de 4 de agosto de 2010. Consulta acerca da inclusão do Empreendedorismo como disciplina no currículo do Ensino Fundamental, do Ensino Médio, da Educação Profissional e da Educação Superior. Brasília: MEC, 2010. Disponível em:

http://portal.mec.gov.br/index.php?option=com_docman\&view=download\&alias $=6$ 552-pceb013-10\&Itemid=30192. Acesso em: 5 fev. 2020.

BUTLER, Judith. O que é crítica? Um ensaio sobre a virtude de Foucault. Tradução de Gustavo H. Dalaqua. Cadernos de Ética e Filosofia política, v. 1, n. 22, p. 159-179, set./dez.2013. Disponível em:

http://www.revistas.usp.br/cefp/article/view/59447. Acesso em: 23 abr. 2020.

CALIXTO, Cláudia. Querer, obedecer e empreender: o governo de si e dos outros nos discursos pedagógicos (final séc. XVIII e início séc. XIX). Tese (Doutorado em Educação). Programa de Pós-graduação em Educação. Faculdade de Educação da USP, 2013.

CARVALHO, Denise. Variáveis associadas ao perfil empreendedor: relações com modelos familiares e formação empreendedora. Rio de Janeiro: UFRRJ, 2004.

CESAR, Maria Raquel. (Des) governos: biopolítica, governamentalidade e educação contemporânea. Revista Educação e temática digital, Campinas, v. 12, n. 1, p. 224-241, jul./dez. 2010.

DARDOT, Pierre; LAVAL, Christian. A nova razão do mundo: ensaio sobre a sociedade neoliberal. São Paulo: Ed. Boitempo, 2016.

DELORS, Jacques. Educação: um tesouro a descobrir. São Paulo: Cortez, Brasília, DF: MEC/UNESCO, 2010.

DOLABELA, Fernando. Empreendedorismo sem fronteiras. Rio de Janeiro: alta Books, 2015.

DOLABELA, Fernando. Oficina do empreendedor. Rio de Janeiro: Sextante, 1998.

DOLABELA, Fernando. Pedagogia empreendedora: o ensino do empreendedorismo na Educação Básica voltado para o desenvolvimento sustentável. São Paulo: Cultura, 2003.

FOUCAULT, Michel. História da sexualidade: a vontade de saber. 10a ed. Rio de Janeiro: Graal, 1990.

FOUCAULT, Michel. Microfísica do poder. Rio de Janeiro: Graal, 2015. 
FOUCAULT, Michel. Nascimento da Biopolítica: curso dado no Collège de France (1978-1979). Tradução de Eduardo Brandão. São Paulo: Martins Fontes, 2008b.

FOUCAULT, Michel. O que é crítica? (Conferência proferida em 27 de maio de 1978). Tradução de Gabriela L. Borges. Edições texto e grafia, 1999.

FOUCAULT, Michel. Segurança, território e população: curso no Collège de France (1977-1978). Tradução de Eduardo Brandão. São Paulo: Martins Fontes, 2008a.

FOUCAULT, Michel. Vigiar e punir: nascimento da prisão. Petrópolis, RJ: Vozes, 1987.

INSTITUTO ENDEAVOR. O prêmio do empreendedorismo: conceitos. 2009. Disponível em: http://www.educacaoempreendedora.org. Acesso em: 02 jun. 2020.

JUNIOR, Otávio Paulo. O espírito do capitalismo e a cultura do empreendedorismo: educação e ideologia. Dissertação (Mestrado em Psicologia). Pontifícia Universidade Católica de Minas Gerais. Programa de Pós-Graduação em Psicologia, 2011.

LAZZARATO, Maurício; NEGRI, Antônio. Trabalho imaterial: formas de vida e produção de subjetividade. Rio de Janeiro: DP \& A, 2011.

MASSCHELEIN, Jan; SIMONS, Martin. Em defesa da escola: uma questão pública. Belo Horizonte: Autêntica, 2017.

NOSELLA, Paulo. A atual política para a educação no Brasil: a escola e a cultura do desempenho. Revista Faz Ciência, v. 12, n. 16, p. 37-56, jul./dez. 2010. Disponível em: http://www.erevista.unioeste.brindex.phpfazcienciaarticle.download. Acesso em: 23 out. 2020.

PELLIZZARO, Nilmar. Michel Foucault: um estudo do biopoder a partir do conceito de governo. Revista Peri, v. 5, n. 11, p. 155-168, jan./abr. 2013. Disponível em: http://www. nexos.ufsc.br/index.php/peri/article/view/888/391. Acesso em: 24 out. 2020.

PERRENOUD, Phillipe. Dez novas competências e habilidades para ensinar. Porto Alegre: Artmed, 2000.

RICARDO, Elio. Discussão acerca do ensino por competências: problemas e alternativas. Cadernos de Pesquisa, v. 40, n. 140, p. 605-628, maio/ago. 2010.

SANTOS, Jane. Política de avaliações externas: a ênfase na questão das competências. Dissertação (Mestrado em Educação). Universidade Estadual de Maringá. Centro de Ciências Humanas, Letras e Artes, 2015. 
SANTOS, Lucíola. Formação de professores na cultura do desempenho: Educação e Sociedade, Campinas, v. 25, n. 89, p. 1145-1157, set./dez 2009. Disponível em: https://www.scielo.br/scielo.php?pid=S01013302004000400004\&script=sci_abstra ct\&tIng=pt. Acesso em: 12 jun. 2020.

SIBILA, Paula. Redes ou paredes: a escola em tempos de dispersão. Rio de Janeiro: Ed. Contraponto, 2012.

SILVA, Márcio. A formação de competências socioemocionais como estratégia para captura da subjetividade da classe trabalhadora. 2018, 169 f. Tese (Doutorado em Educação Escolar) - Universidade Estadual Paulista "Júlio de Mesquita Filho" - Faculdade de Ciências e Letras, Campus de Araraquara/SP, 2018.

TORRES, Rosa Maria. Melhorar a qualidade da Educação Básica: as estratégias do Banco Mundial. In: TOMASI, Luís (Org.). O Banco Mundial e as políticas educacionais. São Paulo: Cortez, 1996, p. 125-191.

VILLELA, Cláudia. Empreendedorismo na escola. São Paulo: Artmed, 2005. 